\title{
Conceito de Liberdade em Vigotski
}

The concept of freedom in Vigotski's theory

Resumo: Este texto sintetiza os fundamentos do conceito de liberdade vigotskiano, procurando elucidar suas conexões a partir das investigações do autor sobre linguagem, vontade, funções psíquicas superiores, pensamento e imaginação. Discutem-se, ainda, os antecedentes filosóficos presentes no seu conceito de liberdade e se esboça uma análise das condições concretas necessárias para a livre-escolha em tempos de alienação.

Palavras-Chave: Liberdade, linguagem, Vigotski.

Abstract: This text summarises the fundamental points of Vygotsky's freedom concept, with the intention of elucidating its connections within his investigations concerning language, will, high mental functions, thought and imagination. We also discuss the philosophic antecedents related to freedom's concept and outline an analysis of the concrete conditions for free choices inside an alienation epoch.

Key Words: Freedom, language, Vygotsky.

\section{Gisele Toassa}

Núcleo de Estudos e Pesquisa: Psicologia Social e Educação:

Contribuições do

Marxismo (NEPPEM UNESP, Bauru-SP]. Apoio financeiro: CAPES.
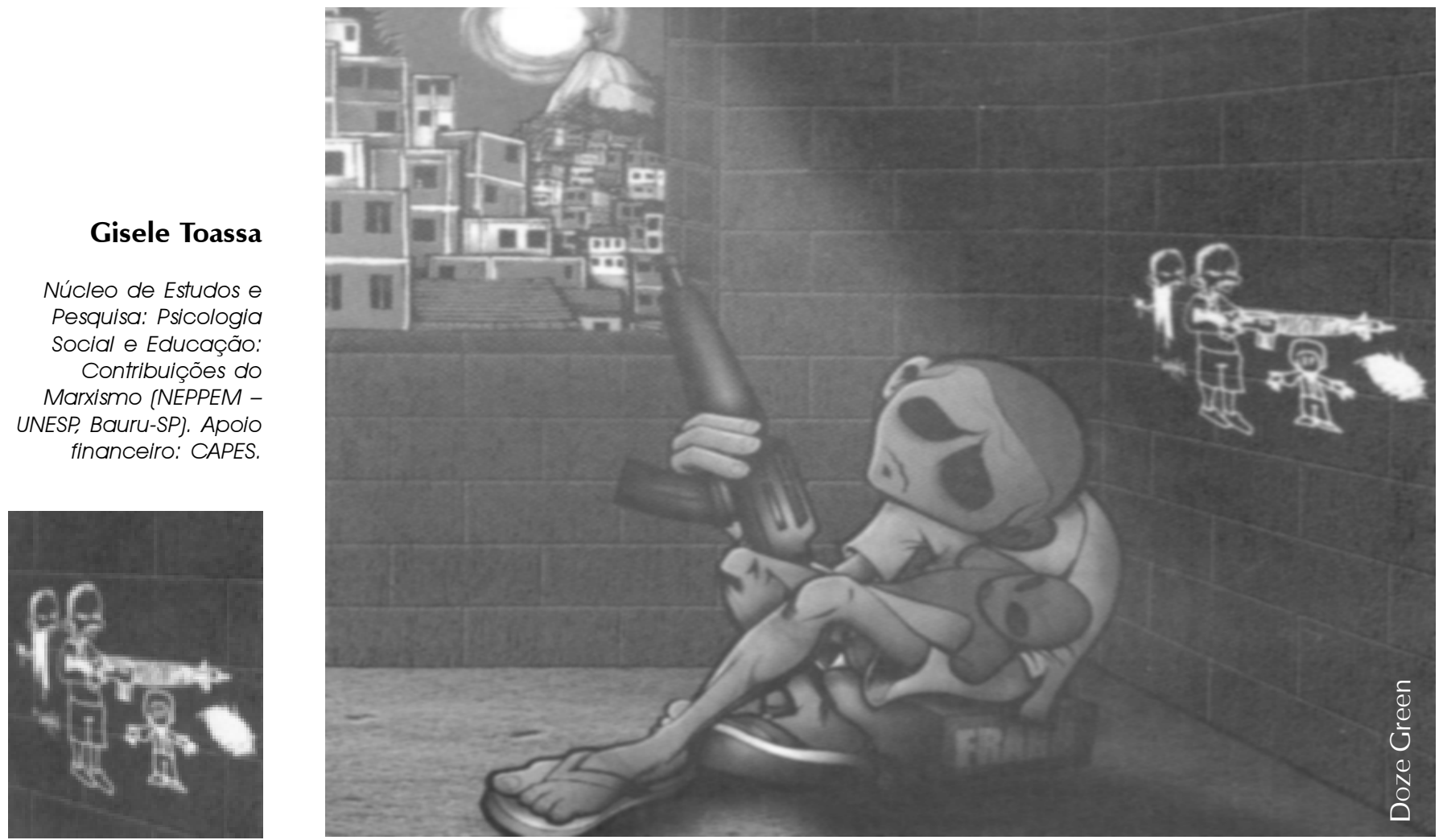

O intuito deste artigo é apresentar os fundamentos para a compreensão do conceito de liberdade em Vigotski, bem como discutir contribuições desse conceito para uma leitura marxista da livre-escolha em nosso tempo

Considera-se que a principal obra na qual Vigotski desenvolve suas noções acerca da liberdade humana é a "História do Desenvolvimento das Funções Psíquicas Superiores" (1995), não obstante apresente idéias esparsas em outros textos. A seguir, procurar-se-á apresentar a contribuição de Vigotski com atenção a uma importantíssima dimensão do trabalho do autor: os fundamentos especificamente humanos do desenvolvimento psíquico.

\section{O Estudos Experimental das Reações Eletivas}

Neste tópico, serão discutidos os experimentos vigotskianos de reação eletiva, os quais incluem o estudo da ontogênese da livre-escolha e suas relações com o domínio da própria conduta. 
Inicia-se com uma questão: em que consiste o processo de domínio das próprias reações e como este se desenvolve? Para Vigotski (1995), esse processo equivale ao domínio das condutas culturais, mediadas pelo signo nas relações sociais concretas; é o processo pelo qual as pessoas passam a escolher suas ações, pensar, ensaiar alternativas. O mote para a análise desses fenômenos foram os experimentos de livreescolha, a forma mais sofisticada de reação eletiva pesquisada.

Vigotski (1995) estudou, na reação eletiva, o processo de formação da conduta mediada por estímulos auxiliares (indicação do adulto, figuras, sorte), que transformam as reações condicionadas, inferiores, em formas superiores, culturais, de reação. Para Vigotski, quando se introduz experimentalmente um meio cultural de resolução entre o homem e o seu objeto consciente, em lugar de um simples vínculo associativo, formamse dois novos vínculos. Isso indicaria que toda transformação pode ser reduzida a processos psíquicos (e nervosos) elementares. O segredo da conduta superior, no entanto, dispõe-se na superação das conexões isoladas. Essencial é a mudança de toda a estrutura do processo de reação. Existiria uma superação da relação associativa imediata entre sujeito e objeto pela criação de um novo processo de comportamento mediado pela cultura.

Vigotski (1995) adota a reação eletiva como a forma mais típica de formação da conduta volitiva, um elo importante no desenvolvimento da personalidade, em que a criança deve perceber, memorizar e/ou comparar estímulos com o auxílio da linguagem. Vigotski estruturou três tipos de experimentos: o primeiro tipo enfocava a atenção mediada por indicadores gestuais e verbais. Organizaram-se tarefas com taças: as crianças deveriam distinguir nexos objetivos entre estímulos pouco diferenciados a partir da indicação do adulto, descobrindo quais taças continham as nozes. No segundo tipo de experimento, investigou-se a memorização mnemotécnica: introduziam-se meios lógicos que tornavam a relação mediada: o estímulo "cavalo", por exemplo, tinha o estímulo-meio "carroça" próximo ao dedo que a criança deveria movimentar. O uso de conexões já preparadas enfocava o próprio processo de compreensão, de ajuste e de estabelecimento das conexões subjacentes à reação eletiva. Vigotski dividiu o processo da reação eletiva em duas fases principais: 1) percepção do estímulo, estabelecimento do nexo devido, e 2) produção da reação correspondente. A reação caracterizava-se bastante claramente com pré-escolares maiores e crianças da escola primária: percebendo a impossibilidade de cumprir a instrução com a memorização, as crianças recorriam prontamente aos estímulos auxiliares.

Já as reações de "livre-escolha" foram estudadas com opções mais complexas do que nos dois primeiros tipos de experimento. Segundo Vigotski (1995), as diferenças entre os experimentos acerca da reação eletiva consistem em que, nas eleições já estabelecidas, o sujeito realiza a instrução, e, nas eleições livres, cria sua própria instrução. As crianças deveriam realizar uma escolha determinada sem modificar as opções oferecidas. O pesquisador indicava opções contendo momentos agradáveis e desagradáveis para os sujeitos, tornando as reações infantis complexas e polissignificativas; em seguida, mediante a indecisão da criança, oferecia-se a ela a opção de tirar a sorte. Vigotski conseguiu criar experimentalmente motivos, ou seja, complexas formações reativas que se estruturam em torno dos estímulos; seriam as reações positivas, negativas ou neutras ao estímulo que o experimentador distribuiu em duas séries de estímulos. A plurissignificação de cada intenção possível concretizar-se-ia numa "luta de motivos" no processo de escolha.

Tamanha foi a importância dos experimentos de livre eleição que Vigotski (1995) utilizou-os para refletir sobre o problema filosófico da liberdade, conceituando-a e expandindo suas conclusões para o âmbito da vida humana:

A liberdade humana consiste precisamente em que pensa, quer dizer, em que toma consciência da situação criada (p.288).

Para Vigotski (1995), os experimentos sobre a livreeleição indicaram que temos liberdade para pensar os estímulos, em operações impossíveis para os animais. Ainda que se coloque uma criança na situação de "paralisia da vontade" (com duas séries de estímulos idênticos), ela poderá utilizar os signos para representação consciente das diversas opções que se precisa conhecer: se escolhe $A$, recebe " $X$ " motivos negativos e positivos; se escolhe $B$, recebe " $Y$ " motivos negativos e positivos. Nesse conjunto, o pensamento mediado por signos é o processo de estabelecimento de nexos, de conexões intermediárias entre o meio auxiliar e os objetos de escolha. A criança precisava dominar a memorização dos nexos preparados, o que significavam para ela; precisava buscar uma definição de conduta quanto às diferentes opções, pesando a relação entre os motivos existentes e as reações possíveis. Confiava a sua decisão à sorte como resultado de um processo final de análise do que estava dado.

\section{A liberdade humana consiste precisamente em que pensa, quer dizer, em que toma consciência da situação criada (p. 288)}

Vigotski

10 estudo documentado por este artigo foidesenvolvido como requisito da disciplina "Desenvolvimento Humano e Educação para as Ciências". no programa de pós-graduação em Educação (Unesp-Bauru), sob a orientação da Profa. Dra. Sueli Terezinh a Ferreira Martins Unesp-Botucatu). 
Mas, realmente, é possível considerar as idéias vigotskianas sobre a liberdade como um conceito independente em seu trabalho? Sim. A liberdade é um conceito que, mesmo sem grande espaço em sua obra, faz-se fundamental para a compreensão do processo de superação das relações condicionadas entre homem e natureza. Esse processo é visto por Vigotski como função de um novo tipo de realidade consciente: a palavra, elemento-chave na ontogênese da conduta superior, o qual cria a possibilidade de representação da realidade ao invés da simples reação imediata aos estímulos já existentes.

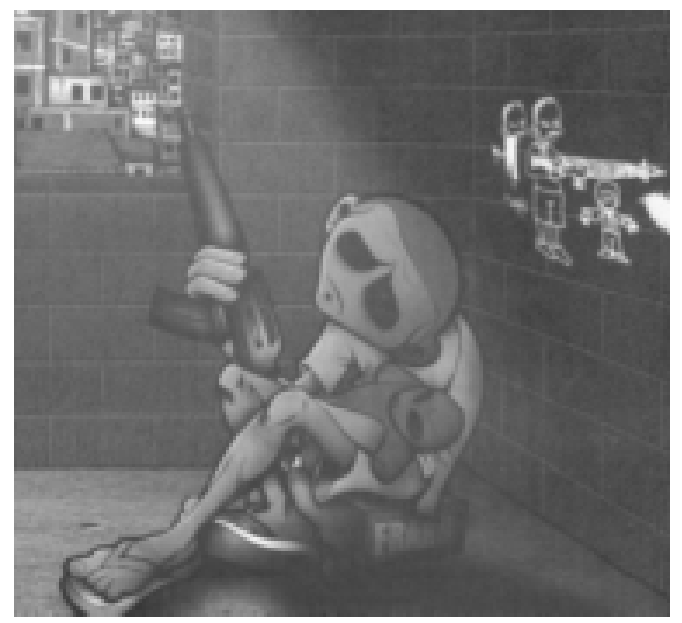

Vigotski (1995) elevou suas idéias sobre a liberdade para além das simples conclusões experimentais: segundo ele, os problemas em que a sorte era o principal fator configuravam uma espécie de "filosofia experimental", isto é, forneciam base para a compreensão do problema do livre arbítrio, de problemas éticos em que o sujeito deve acatar uma ação e desejar a outra, superando as relações condicionadas que regem o comportamento animal. Ante o psicólogo genético, impor-se-ia a tarefa de encontrar as vias de desenvolvimento de livre-arbítrio. Para Vigotski, deve-se explicar a liberdade como um produto do desenvolvimento progressivamente incrementado - esse ideário é indissociável da questão que dirigiu a obra de Vigotski: o estudo da manifestação mais superior da psique: a consciência humana (Leontiev, 1996), que transcende a pesquisa das reações compartilhadas por seres humanos e animais.

Acrescente-se que Vigotski (1995) propôs seus experimentos sobre a reação eletiva numa seqüência de gradativa complexidade, culminando com o estudo do processo de formação da livre-escolha - esta não ocorreria por acaso, mas, sim, graças ao desenvolvimento das funções psíquicas superiores (atenção e memória) na reação eletiva, anteriormente estudadas pelo autor. Tais funções não se isolam na consciência humana, mas desenvolvem-se em conjunto, num processo de constituição de uma estrutura superior de consciência. Esse ponto toca o que há de essencial no conceito vigotskiano de liberdade: a tomada de consciência, processo constituído numa relação dinâmica entre pensamento e linguagem. Para Vigotski (1995), os processos decisórios, desde as escolhas mais primitivas, seriam função dessa relação. A natureza propriamente psicológica dos signos serve não a realizar diretamente mudanças nos objetos físicos, mas, sim, na representação psíquica dos estímulos produzidos por tais objetos e na regulação dos atos motores, inclusive no uso de ferramentas na atividade prática. Interagindo, as pessoas apropriam-se de uma ação com objetos e, seja no seu contexto de apropriação, seja posteriormente, utilizam a nova reação para a resolução de um problema. O caminho do pensamento passa primeiramente pelo processo de análise e as reações já desenvolvidas pela criança ou que podem ser desenvolvidas na própria situação nova.

Mas o domínio da própria conduta no contexto dos experimentos vigotskianos mediaria atos livres, ou seja, conscientes?

Vigotski (1995) reflete que, de certo modo, nos experimentos de livre-eleição, expressam-se escolhas o mais rigidamente determinadas e o menos livres possível. A única participação da criança era dotar um certo conjunto de estímulos neutros de um novo sentido, conferindo ao seu próprio gesto de jogar - de resultado imprevisível a resolução do impasse. Eis o que Vigotski denomina de "uma contradição dialética contida no livre arbítrio, experimentalmente fracionada" (1995, p. 289). A participação consciente da criança consistiria na formação da intenção que se realizaria,a partir daí, segundo nexos condicionados - isso porque o domínio de nossas reações motoras continua sendo um processo natural.

É necessário, no entanto, formular uma pergunta. Como se poderia entender a reação de livreescolha no contexto da vida humana concreta? Resposta: entendendo a complexa relação entre as determinações de nossas escolhas e o processo de pensamento a elas relacionadas, que não só se define em função do que existe objetivamente, como também cria novas escolhas a partir do que já existe. A intenção livremente estabelecida não é caudatária de uma cognição asséptica, mas, sim, ato de uma individualidade consciente, em que se inscreve a história de interações humanas - até mesmo a história dos motivos constituídos pelas 
pessoas. Vigotski (2001) afirma que o pensamento nasce do campo da consciência que o motiva, a qual abrange os pendores e necessidades, os interesses e motivações, os afetos e as emoções. Desse modo, para Vigotski (2000), uma vez que a pessoa pensa, é necessário perguntar que pessoa o faz. O autor compara a Psicologia a um drama, com "lutas" radicalmente distintas de um processo de reflexão estática da realidade na consciência, lutas em que a simples adoção de um significado externo não resolverá o problema existente. Tornar-se livre é, portanto, assimilar um significado diferençando-se dele - é tornar-se indivíduo humano que recria a realidade na consciência, constituindo um ativo conhecimento das determinações da conduta e, nesse processo de conhecimento, modifica a realidade objetiva (natural e/ou social).

Desse modo, uma relação entre a noção de motivo para Vigotski e a sua concepção geral de consciência esclarece que tornar-se livre é um processo racional, implicado na apropriação concretamente determinada da vida humana. Isso se representou nos experimentos de livre-escolha: quando se propuseram para a criança estímulos polissignificativos, a escolha era um imperativo situacional que deixava possibilidades em aberto. A opção pela sorte, na dinâmica da reação eletiva, refletiria uma tomada de consciência do sujeito com relação à estimulação conflitiva proposta pelo experimentador, em que a criança sempre teria de renunciar a algum motivo.

Para o fechamento deste tópico, é ainda necessário reconstituir o significado do termo-chave para o conceito de liberdade vigotskiano: a tomada de consciência. Se, no texto "História do Desenvolvimento das Funções Psíquicas Superiores" (1995), "pensamento" e "tomada de consciência" são equivalentes, podemos afirmar que essa equivalência passa pela relação entre pensamento e palavra, especialmente, pelos conceitos científicos. Trazem-se, então, elementos de outros textos vigotskianos para esclarecer tal relação: em "A Construção do Pensamento e da Linguagem" (2001), o autor afirma que tomar consciência de uma operação significa recriá-la na imaginação para que seja possível exprimi-la em palavras. Tal processo é destacado da atividade geral da consciência, tornando-se, ele mesmo, objeto consciente - apreendem-se os próprios processos psíquicos através da generalização e sistematização existente no conhecimento científico.

Afirma-se que os experimentos sobre livre-eleição, relatados na "História do Desenvolvimento das Funções Psíquicas Superiores" (1995), não coincidem, absolutamente, com o nível superior de consciência representado pela apropriação de conceitos científicos. No entanto, o comentário de Vigotski (1995) acerca das reações de livreescolha refere-se a que a criança "toma consciência" da igualdade de opções, solucionando-a pela introdução de um meio: a sorte. Considera-se que, tanto nas reações de livreescolha quanto no processo de pensamento científico, a linguagem medeia a recriação da realidade na consciência - mas supõe-se que o processo experimental trate de um nível prático de tomada de consciência, em que a realidade refletida espontaneamente na linguagem corresponda efetivamente à organização experimental dos motivos nela presentes. São os primórdios da auto-determinação humana.

\section{Ontogênese da Relação entre Linguagem, Consciência e Liberdade}

Além de verbalizar o pensamento, possibilitando a análise da realidade a princípio refletida indiferenciadamente na consciência, a linguagem presta-se à regulação da passagem de uma reação à outra, ou seja, ao domínio da conduta, nos seus primórdios,realizada externamente. Para Vigotski (1995), o caminho da coisa à criança e da criança à coisa passa por outra pessoa, tendo o uso dos signos como mediação - a fala egocêntrica exibe objetivamente esse processo: ora a criança fala, analisando a situação e agindo sobre ela, ora solicita o auxílio do adulto. Todo esse processo experimental de interação da criança com o outro e consigo mesma ilustra a ontogênese do domínio da própria conduta, fundamento consciente da constituição dos atos livres. A fala egocêntrica comanda a percepção e memória da criança, fazendo-a compreender as relações concretas que determinam sua atividade; posteriormente, com a internalização das funções psíquicas superiores, transforma-se em uma relação verbal entre o indivíduo e sua própria consciência: é a chamada linguagem interior, uma forma de pensamento verbal que torna a realidade subjetiva e consciente. Assim, a vontade não é uma função psíquica, mas o próprio comando das diferentes funções e do estabelecimento de intenções concretas (baseado em Vigotski, 2000), pelas quais a pessoa converte a ação condicionada em ação livre.

E qual seria a origem social da vontade? O domínio externo do próprio comportamento. Para Vigotski (1995), a palavra é, a princípio, uma relação social entre a criança e os indivíduos mais desenvolvidos, relação em que se exerce poder sobre o comportamento infantil - isso é verdadeiro, principalmente na primeira infância. $O$ domínio da própria conduta consiste no processo de internalização da influência estimuladora da 
palavra: daí, as pessoas aprendem a relacionar-se com sua própria consciência como se fosse com outra pessoa. Segundo Vigotski (2000), a vontade, num nível físico, pode ser considerada como um processo de humanização do próprio cérebro (relações entre os centros nervosos) partindo de sua relação com a realidade externa. $O$ autor (2001) afirma que a passagem a uma estrutura superior de consciência pode ser identificada num novo emprego significativo da palavra, no seu emprego na formação de conceitos - eis a causa psicológica imediata da transformação intelectual que se realiza no limiar entre infância e adolescência.

Toda penetração mais profunda na realidade exige uma atitude mais I'vre da consciência para com os elementos dessa realidade, um afastamento do aspecto externo aparente da realidade dada imediatamente na percepção primária, a possibilidade de processos cada vez mais complexos, com a ajuda dos quais a cognição da realidade se complica e se enriquece.
Diversamente dos experimentos de livre-escolha, todavia, na vida concreta, o indivíduo pode modificar as condições que determinam sua conduta, criando uma nova solução. $O$ processo de constituição de um sentido para o mundo e suas relações já seria uma forma de criação de novas combinações: não é a realidade que simplesmente "se reflete" na consciência, mas também o indivíduo que a reflete ativamente, produzindo, no conceito, uma nova versão da realidade. Aí se atinge um ponto importante da obra vigotskiana: a relação entre imaginação, liberdade e atividade criadora. Para Vigotski, o desenvolvimento da linguagem constitui um forte impulso para a imaginação, oferecendo à criança a possibilidade de representar, para si mesma, algum objeto que não tenha visto e pensar nele. Um excerto:

Toda penetração mais profunda na realidade exige uma atitude mais livre da consciência para com os elementos dessa realidade, um afastamento do aspecto externo aparente da realidade dada imediatamente na percepção primária, a possibilidade de processos cada vez mais complexos, com a ajuda dos quais a cognição da realidade se complica e se enriquece.

Desejaria, finalmente, dizer que a conexão interna existente entre a imaginação e o pensamento realista complementa-se com um novo problema, intimamente ligado ao da vontade ou liberdade na atividade do homem, na atividade da consciência humana. As possibilidades de agir com liberdade, que surgem na consciência do homem, estão intimamente ligadas à imaginação, ou seja, à tão peculiar disposição da consciência para com a realidade, que surge graças à atividade da imaginação (Vigotski, 1999b, pp.129-130).

A citação acima apresenta, com força inegável, a implicação da imaginação com a "liberdade de movimento da consciência" no que se refere à realidade objetiva. Para Vigotski (1994), a imaginação é um processo psicológico novo, representando uma forma especificamente humana de atividade consciente. Em Vigotski (1999b), a imaginação pode ser "autista" ou "realista" (categorias não necessariamente dicotômicas), mediando a atividade criadora. Segundo ele (1987), a atividade criadora seria toda realização humana que cria algo : reflexos de algum objeto, uma construção do cérebro, sentimentos que vivem e se manifestam só no próprio ser humano (as fantasias). A criação coletiva, que abrange todos os acréscimos insignificantes da criação individual, torna possível compreender as inúmeras criações anônimas do gênero humano. Criar (processo hoje erroneamente encarado como prerrogativa das artes ou das ciências) é uma atividade relacionada às necessidades especificamente humanas de transformação das condições naturais e sociais.

\section{Influências Filosóficas}

Deve-se considerar que a obra de Vigotski é essencialmente marxista. Pino (2000) afirma que Vigotski encontra no materialismo histórico e dialético o "núcleo duro" de sua obra, ou seja, o principal núcleo gerador do seu pensamento teórico e metodológico. Sua psicologia é dotada dos princípios do marxismo e também de uma teia conceitual própria, criativa, que não obedece a uma pronta correspondência com as obras de Marx e Engels. Conforme Shuare (1990), corresponde a Vigotski o mérito de aplicar criativamente o materialismo dialético e histórico à Psicologia e nela ter provocado uma verdadeira revolução copernicana.

Contudo, é importante assinalar a influência de Espinosa na obra vigotskiana. Talvez suas reflexões sobre a liberdade sejam o maior exemplo concreto dessa influência, ainda assim permeada pelo marxismo - seria errôneo encarar suas idéias sobre a liberdade a partir de uma única influência filosófica.

Vigotski (1995) compara os experimentos sobre a livre-escolha com a análise espinosana de um antigo problema lógico, o chamado problema do "asno de Buridan": nele, propõe-se que um asno faminto está parado diante de duas pilhas de feno eqüidistantes. Para Vigotski, na vigência da lei natural do reflexo condicionado, em que estímulos e reações se processam automaticamente, o animal perecerá de fome - pois os estímulos equiparamse. Pavlov comprovara, com cães, fenômenos de neurose experimental, apresentando aos animais motivos contraditórios entre si. Mas, e o homem, o que faria numa situação semelhante? Para Espinosa, pensaria (conforme Vigotski, 1995).

Vigotski (1995) assinala que, segundo Espinosa, a vontade não é livre, mas, sim, dependente de 
motivos externos. Vigotski admite que o problema atribuído a Buridan encerra uma idéia profunda e certeira: perde-se a ilusão do livre arbítrio quando se analisa o determinismo da vontade, sua dependência dos motivos. O autor sublinha, nesse texto, a importância do trabalho inacabado: "A Teoria de Espinosa Sobre as Paixões à Luz da Neuropsicologia Moderna" ${ }^{2}$. Esse trabalho foi editado na tradução norte-americana do tomo VI das Obras Escolhidas de Vigotski, com o título "Teaching about Emotions. Historical-Psychological Studies" (1999a). Nele, ganha importância a seguinte interpretação vigotskiana: para Espinosa, a liberdade não se consubstancia na idéia de "livrevontade" (free will), mas, sim, "livre-necessidade" (free necessity), elemento que muito se aproxima da discussão vigotskiana sobre a "necessidade gnoseológica". Essa idéia é discutida na interpretação dos experimentos de livre-escolha: o livre-arbítrio não significaria, para Vigotski, que a criança esteja livre dos motivos para decidir, mas que "toma consciência da situação, toma consciência da necessidade de eleger, que o motivo se impõe a ela e que sua liberdade no caso dado, como diz a definição filosófica, é uma necessidade gnoseológica" (1995, p.289). Assim, o ser humano cria uma nova necessidade, a necessidade de conhecimento - e a nova necessidade é, de algum modo, expressão da natureza, como o deus espinosano. Ao finalizar o capítulo "domínio da própria conduta" (1995), em que expõe com maior vagar do seu conceito de liberdade, Vigotski antecipa:

Não podemos analisar, aqui, em toda sua plenitude, a perspectiva filosófica. Confiamos em poder fazê-lo em outro trabalho dedicado à filosofia. Intentaremos esboçá-la tão só para tomar clara consciência do ponto a que chegamos. Não podemos deixar de assinalar que nossa idéia da liberdade e o autodomínio coincidem com as idéias que Espinosa desenvolveu em sua "Ética" (1995, p. 301).

A prematura morte de Vigotski deixou inacabado o texto "Teaching about Emotions", para o qual prometera uma explanação filosófica "espinosana" acerca da liberdade humana e do autodomínio. É pena, particularmente porque, exatamente uma página antes de comentar a coincidência de suas noções com as de Espinosa, Vigotski (1995) aprova reflexões de Engels. Vigotski interpreta que, para Engels, o domínio da natureza equipara-se ao autodomínio: o livre arbítrio não constituiria mais do que "tomar decisões com o conhecimento do assunto". Vigotski cita o seguinte comentário de Engels:

Por conseguinte - disse Engels - a liberdade consiste fundamentalmente em conhecer as necessidades da natureza [...] em saber dominar tanto nossa própria natureza como a exterior; por isso, é um produto imprescindível do desenvolvimento histórico. Os primeiros homens surgidos do mundo animal não tinham essencialmente uma liberdade diferente da dos próprios animais, mas cada passo dado pelo caminho da cultura era um passo à liberdade (Engels, in Vigotski, 1995, p. 300).

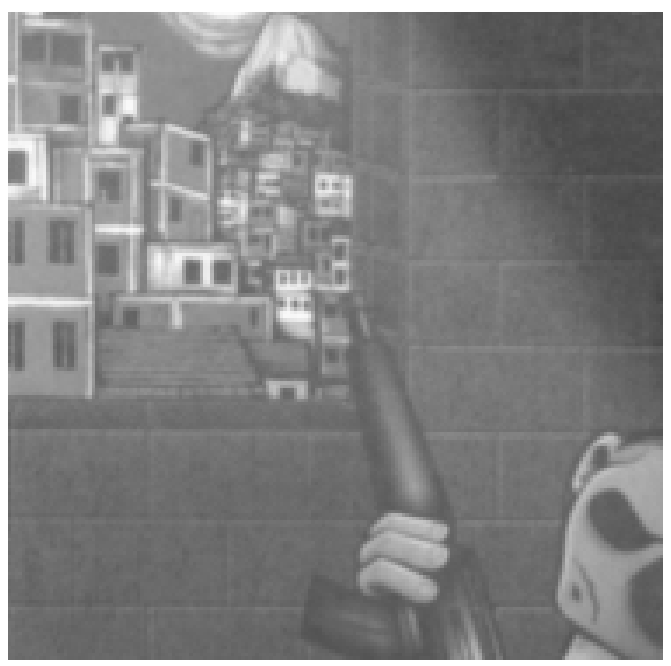

Desse modo, o conceito de domínio da própria conduta, ou autodomínio, é, para Vigotski, um aporte de tendências marxistas e espinosanas - de resto, ambas materialistas. Tendo em vista essa aproximação, é essencial destacar que a chave da "tomada de consciência" é a cultura que medeia o domínio humano das influências naturais (inclusive o domínio da própria natureza biológica do homem) e, no entanto, às vezes não se presta a outro objetivo além de suprir necessidades naturais. Não foi sem razão que Marx apontou a economia - ou seja, o submetimento da natureza na forma de relações de produção - como o eixo estruturador de todas as sociedades humanas, e o trabalho como fundamento concreto da reprodução da própria vida. Daí encontrar-se, em Vigotski, a liberdade como "livre-necessidade", "necessidade gnoseológica": uma nova necessidade que consiste na atribuição de novos sentidos às informações sensoriais, na aprendizagem do uso de instrumentos e na criação de novos meios de domínio da realidade natural, necessidade cuja origem pode ser compreendida com base nas relações sociais mediadoras da relação homem-natureza. Sobre a natureza, lembremo-nos também da importância dos processos associativos elementares, herança da espécie, na constituição da conduta mediada. Vigotski (1999a) não foi um idealista: na companhia de Espinosa, criticou duramente o idealismo cartesiano, para quem a vontade humana (à moda dos estóicos) é inteiramente livre. Para Vigotski (1995), se a natureza determina a
Desejaria, finalmente, dizer que a conexão interna existente entre a imaginação e o pensamento realista complementa-se com um novo problema, intimamente ligado ao da vontade ou liberdade na atividade do homem na atividade da consciência

humana. As possibilidades de agir com liberdade, que surgem na consciência do homem, estão intimamente ligadas à imaginação, ou seja, à tão peculiar disposição da consciência para com a realidade, que surge graças à atividade da imaginação

Vigotski

2 Título traduzido do russo por Paulo Bezerra (in Vigotski, 2001). 
conduta, é a criação dos meios de domínio da natureza que tornam o homem livre. $O$ autor ainda afirma que, na transferência de uma "luta de estímulos" para a "luta de motivos", modifica-se a força relativa dos estímulos. Estímulos mais fortes podem converter-se em mais fracos: um homem pode declarar-se em greve de fome para defender algum princípio. A primazia do significado impõese sobre o imediatismo natural, modificando tanto a consciência quanto a realidade objetiva. Portanto, modifica-se a própria causalidade das ações humanas, mas tanto as necessidades do organismo biológico (qualitativamente modificadas pelas práticas sociais) quanto as da sociedade cujos motivos internalizamos devem ser determinações constitutivas da escolha livremente estabelecida.

\section{Considerações Finais: Implicações do Conceito de Liberdade Vigotskiano}

Para Vigotski (1999b, p.140), “a vontade refere-se a que, em certas condições, o homem converte a ação determinada, causal, condicionada, em ação livre". A vontade é dinâmica, determinada e desenvolve-se, incrementando a liberdade individual - e, para tanto, Vigotski fala em "certas condições", sem especificá-las. Hoje, qualquer tentativa de sistematizá-las está, de certo modo, condenada ao terreno da especulação teórica. Entretanto, aceita-se o risco de introduzir o debate acerca das condições psicossociais necessárias para a ontogênese da reação de livre-escolha, justificando tal introdução pela importância do conceito de liberdade vigotskiano para a crítica do idealismo na Psicologia e na Educação; em ambas as áreas porque, na esteira de Vigotski, podemos dizer que a liberdade não é uma capacidade magicamente presenteada ao homem, mas, sim, um fenômeno ontogenético indissociável das relações sociais já existentes. Conhecer as condições necessárias para a livre-escolha é um passo necessário para analisá-la e mediar seu processo de constituição.

Os experimentos de livre-escolha refletem a ação livre num nível ainda primitivo de domínio da própria conduta; no que se sabe, a atividade de criação de novas soluções não se constituiu em objeto de estudo experimental para Vigotski (embora a atribuição de novos sentidos aos meios de domínio da própria conduta sejam, de certo modo, criação ativa de novas conexões pelo indivíduo, sem se confundirem com as atividades de criação mais elevadas). No entanto, como será exposto, as condições de reação existentes nos experimentos de livre-escolha - por mais simples que sejam - são raridade em tempos de alienação. A ontogênese da liberdade individual, como superação das leis do reflexo condicionado através da palavra, mostra-se amplamente comprometida, desde a esfera da educação até a do trabalho.

Com base nos experimentos de Vigotski (1995), indicam-se as seguintes condições psicossociais necessárias à reação de livre-escolha: 1) a linguagem (sistema de sinais arbitrários); 2) a necessidade objetiva de escolher entre motivos significativos (e conflitivos) para a pessoa; 3) a possibilidade de estabelecer os fins das próprias ações; 4) uma relação ativa com os objetos de escolha, atribuindo-se um novo sentido consciente aos motivos existentes; 5) um nível de domínio das funções psíquicas superiores ao menos correspondente à idade pré-escolar superior, e 6) a aprendizagem sociocultural das ações humanas com instrumentos (que, nos experimentos de livreescolha, seriam representados pelos meios para se lançar a sorte).

As condições enumeradas são indissociáveis, sendo a linguagem o eixo estruturador das demais condições: transpõe as funções psíquicas a um nível superior de conduta, medeia a aprendizagem do uso de instrumentos, representa a realidade num novo sistema de sinais, medeia a assimilação dos motivos significativos numa dada cultura, além de possibilitar o ativo desenvolvimento do domínio da própria conduta na relação com os seres mais desenvolvidos. Levando-se em consideração que a ontogênese da liberdade inscreve-se num processo de desenvolvimento humano determinado pelas comentadas condições psicossociais, discutirse-ão algumas determinações sociais em que se inscreve a livre-escolha (ou a sua ausência), além dos processos de criação não contemplados pelos experimentos vigotskianos, apesar de imbricados em suas idéias sobre liberdade.

O processo de desenvolvimento da livre-escolha demanda tanto a necessidade concreta de escolher quanto a possibilidade de definir novas opções, mas, no capitalismo, o poder econômico determina as possibilidades de escolha existentes. A tendência das relações humanas é fundamentarse na exploração dos não-detentores dos meios de produção por aqueles que os detêm. Isso se torna particularmente dramático no que se refere à relação entre homem e natureza: sendo a alienação a expropriação tanto dos meios de produção quanto dos fins da mesma, a pessoa não mais determina seu próprio trabalho. Este passa a significar, então, uma forma de escravidão às próprias necessidades naturais, pois é em função delas que o indivíduo se sujeita ao domínio alheio, o qual determina as únicas opções de comportamento possíveis. $O$ trabalhador precisa, em primeiro lugar, manter-se vivo: a falsa escolha colocada é entre morrer ou viver explorado - 
dizemos "falsa escolha", porque nos parece que a defesa da vida acaba (quase sempre!) sendo a única opção razoável. Não há "livre-necessidade", para usar uma expressão espinosana, se a necessidade de sobrevivência deforma e descaracteriza todas as outras necessidades, sobrepujando-as pela carência de opções na realidade concreta.

Alienado dos meios e fins da produção, o indivíduo pode tão-somente reproduzir a si mesmo e ao mundo, que tende a tudo igualar, existindo poucas ocasiões em que se realizam "lutas de motivos" no plano das relações sociais; os motivos estranhos à sobrevivência precisam ser sufocados pela impossibilidade de se consubstanciarem numa nova intenção. Não é de se estranhar a dilatação da imaginação autista, atividade puramente emocional que conforta o indivíduo enquanto o protege dos motivos coercitivos, constituintes de sua realidade concreta. A contradição hipócrita entre a ideologia do esforço pessoal e a pobreza concreta de situações em que essa falsa palavra se realize torna-se uma fonte de sofrimento psíquico no trabalho, em que o significado irracional da submissão submete a análise racional do mundo.

Em geral, apenas no tempo livre o trabalhador pode criar melhores condições para sua existência. As contradições do capital acabam legando ao indivíduo apenas a sua própria força de trabalho, que pode ser empregada em seu tempo livre conforme lhe dite a consciência. E, embora as pessoas sejam um tanto mais livres no processo de atribuição de novos sentidos às situações de sua realidade doméstica, são poucas as alternativas de uso reflexivo da palavra (ou seja, a discussão) na esfera pública. Hoje, subsiste a carência de atividades culturais, científicas e políticas a partir de cuja apropriação o ser humano possa tomar consciência do seu processo de vida real, assumindo uma nova e intencional relação com o mundo que o cerca. Vigotski (1996) não foi ingênuo quanto à liberdade do indivíduo, ao dizer que sermos

donos da verdade sobre a pessoa e da própria pessoa é impossível enquanto a humanidade não for dona da verdade sobre a sociedade e da própria sociedade. Ao contrário, na nova sociedade nossa ciência se encontrará no centro da vida. "O salto do reino da necessidade ao reino da liberdade" colocará inevitavelmente a questão do domínio de nosso próprio ser, de subordiná-lo a nós mesmos (p. 417).

Existiria, entretanto,no capitalismo, um maior leque de escolhas com relação aos modos de produção anteriores. Marx (1974) observa que a consciência (ou ilusão) de uma determinação pessoal livre faz do assalariado um trabalhador muito melhor do que o escravo - todavia, a liberdade burguesa, para Marx (segundo Oliveira, 1997), é uma liberdade abstrata: a formalidade da livre disposição sobre o seu próprio ser opõe-se à objetividade material que impossibilita ao trabalhador a livre escolha sobre a venda ou não de sua força de trabalho.

A escolha de valores éticos também tornou-se possível no universo do capital. Os indivíduos podem, contraditoriamente, constituir um novo sentido para o trabalho, sentido que negue intencionalmente os valores alienados (competição, individualismo, bajulação etc). Cindido em atividades e ainda escravo da sociedade que medeia a relação com sua essência individual, é possível ao trabalhador a livre-criação e participação nas lutas ético-políticas (sindicatos, partidos, conselhos etc), além da criação artística (teatro, dança, música etc). Para tais possibilidades, no entanto, é essencial a constituição de motivos negativos da dominação e a aprendizagem de novas reações humanas - daí a necessidade tanto da educação regular quanto dos processos formativos nos espaços que se pretendam alternativos à dominação.

Para a classe média, surgem como possibilidade as profissões científicas, artísticas e tecnológicas, a partir das quais o indivíduo pode buscar o domínio de novas aprendizagens. A atividade criadora, apesar disso, dificilmente existe no trabalho, e, quando se realiza, subordina-se também ao poder que determina os parâmetros básicos da criação: é o caso da publicidade, da ciência ou da produção de novas tecnologias. Em alguns casos, ainda que sua produção seja determinada pelo mercado, o sujeito pode apresentar sua contribuição criativa para a transformação das necessidades sociais e das suas próprias - assim, sua produção pode converter-se numa livreescolha. No entanto, a submissão dos produtores ao imperativo objetivo do lucro pode trabalhar contra a democratização da produção: é o caso de muitos tratamentos especializados, existentes fora do atendimento básico de saúde. Necessário é compreender que, entre as condições para a livre-escolha, o indivíduo deve determinar suas próprias reações - e essa possibilidade costuma ser subjugada pelos fins alienados da realidade concreta. Desenha-se a ontogênese de uma ação livre algo marginal e esquizofrênica.

Acrescente-se que, numa sociedade permeada por contradições, quase todas as condições psicossociais para a livre-escolha são compráveis: a possibilidade de definir fins e atividades, de realizar novas aprendizagens (desenvolvendo suas funções psíquicas superiores), os instrumentos de ação, a linguagem (principalmente como veículo da ideologia dominante). A acumulação de uma

Sermos donos da verdade sobre a pessoa e da própria pessoa é impossível enquanto a humanidade não for dona da verdade sobre a sociedade e da própria sociedade. Ao contrário, na nova sociedade nossa ciência se encontrará no centro da vida. "O salto do reino da necessidade ao reino da liberdade" colocará inevitovelmente a questão do domínio de nosso próprio ser, de subordiná-lo a nós mesmos.

Vigotsk 
experiência cultural que possibilite a criação do novo está, de modo geral, mais próxima do rico que do pobre. Quanto mais dinheiro, maior a variedade de escolhas que se pode fazer; entretanto, geralmente são falsas escolhas, que se esgotam no consumo e não apontam para a criação de novas necessidades mediadas pela cultura. As pessoas são agentes, fundamentalmente, ao comprar, necessidade que supre o vazio de sentido das demais relações que submetem suas vontades, nas quais a opção define-se antes da ação. No consumo, a realidade apresenta-se como um mundo em que não há conflito de motivos: aparentemente, apenas o positivo se sobressai, apenas o prazer subjetivo define intenções irrestritas. Mas, se existe um maior número de (falsas) opções, tais opções estão determinadas pela eficiência do burguês em explorar - uma necessidade que o torna escravo de sua própria condição de explorador e dos valores (motivos) já existentes no universo da exploração.

Outra questão: pudemos perceber que o processo de conhecimento não pode ser eliminado da livreescolha; no entanto, nas relações de dominação, existe uma ampla alienação com relação à aprendizagem da cultura mediadora do desenvolvimento psíquico: produtos culturais e educacionais transformam-se em mercadoria, bem como os meios de produção historicamente desenvolvidos. E o que dizer da marcante presença da práxis repetitiva em muitos ramos da produção e da educação capitalista? Não podem ser chamadas de livre-escolha. Vigotski (1995) distingue a simples reação eletiva da livre-escolha justamente porque, num caso, o mecanismo executivo formado pela criança meramente ajustase às instruções externas e, no outro, a criança decide-se a utilizar os meios auxiliares, preparando o aparato funcional da ação, ou seja: determina os fins das próprias ações a partir das possibilidades existentes. Quando não se incentiva a necessidade objetiva de compreender os motivos de ação e escolher entre eles, tampouco é mediada a ontogênese do domínio da vida real. Com a alegação de que o aprendiz não sabe escolher, ignora-se que a liberdade humana se desenvolve na própria atividade de escolha. $\mathrm{Na}$ "escoladecoreba", a imposição da mnemotécnica é toda a atividade, raramente criando-se a necessidade objetiva de que o educando pense e crie suas próprias instruções - ao invés de uma relação ativa com a própria vida, da primeira à última idade o indivíduo é dessubjetivado, passivo diante das necessidades socio-históricas.

Como diz Vigotski (1987) acerca das artes: uma compreensão justa e científica da Educação não sentimentos ou critérios alheios às crianças. A

liberdade de criação é importantíssima para o resultado da obra: uma simples imposição da escrita adulta pode restringir a criança a elaborar textos puramente formais. Limitando-se as possibilidades concretas de reflexão, a palavra presta-se fundamentalmente ao domínio social, ao poder que estranha a elaboração de um sentido consciente e de reações livremente determinadas. Eis um novo paradoxo: o indivíduo deve dominar sua própria natureza, mas de acordo com necessidades externas a ele. Esse ponto agrava-se porque, para Vigotski (1995), caso se queira saber como funciona a palavra na conduta do indivíduo, deve-se analisar, antes de tudo, qual foi sua função anterior no comportamento social das pessoas. A palavra consiste na mediação do processo intencional de representação da realidade; sua natureza parte da própria natureza social dos homens, cujas necessidades são de um "animal político", que só pode isolar-se em sociedade (Marx, 1999). Se a dominação acontece nas relações com outros indivíduos, apenas em relação com eles é possível criar novos sentidos para as ações - e a primeira condição para isso é a possibilidade de falar sem coerções. Não é sem sagacidade que as religiões fundamentam-se na criação de tabus, ou seja, temas intocáveis: o que não se discute não se muda, apenas se acata. Uma experiência cultural, quando unilateral, cria significados únicos, que são realidade imutável a partir da qual não se enxergam novos horizontes.

Na ontogênese, nunca há sentidos a priori: para cada novo indivíduo, a atividade consciente é um processo de recriação dos significados convencionais à sua classe. Assim, diz Vigotski (1994): "Em um sentido, no brinquedo, a criança é livre para determinar suas próprias ações. No entanto, em outro sentido, é uma liberdade ilusória, pois suas ações são, de fato, subordinadas aos significados dos objetos, e a criança age de acordo com eles" (p.136). Tornar-se livre no interior de uma sociedade significa, assim, internalizar seus nexos discursivos, mas não é possível reduzir esse processo à simples apropriação da ideologia dominante: com a reflexão da realidade na palavra, esta se transforma em substância da consciência individual e das relações sociais. Haja vista, por exemplo, a eleição de Lula: conquanto tivesse sido rotulado pela grande burguesia como "nordestino burro" (rótulo aceito até mesmo pelas classes populares), foi eleito com uma expressiva votação. Qualquer ser humano que se aproprie da linguagem é, de algum modo, livre, pois a palavra não é reflexo estático da realidade na consciência. É também pensamento e comunicação, é expressão de determinadas lutas de motivos embora o controle do discurso seja, sem dúvida, a mais eficiente forma de dominação material do processo de tomada de consciência. 
Este artigo encerra-se, aqui, como uma primeira aproximação ao conceito vigotskiano de liberdade. Falta muito a se fazer. Sequer se discutiu, por exemplo, o processo de tomada de consciência através dos conceitos científicos; sequer se discutiu o rascunho "Psicologia Concreta do Homem" (2000), em que Vigotski comenta a psicologia dos papéis sociais como um "drama" e as "lutas de motivos" no plano das necessidades afetivas. A psicologia marxista ainda precisa empenhar-se na investigação dessas esferas, negando a desumanização que torna a palavra um instrumento de domínio, quando é "a palavra que faz livre a ação humana" (Vigotski, 1999b, p. 68).
Gisele Toassa

Al. dos Goivos, 7-35, Pq. São Geraldo, Bauru - SP. CEP 17021-260. E-mail:gi_toassa@hotmail.com
LEONTIEV, A. N. Apêndices. In Teoria e Método em Psicologia. São Paulo: Martins Fontes, 1996, pp. 425-470.

MARX, K. El Capital, libro I, capítulo VI. Córdoba-BA: Siglo XXI, 1974. . Para a Crítica da Economia Política. São Paulo: Nova Cultural (originalmente publicado em 1859).

OLIVEIRA, A.R. Marx e a Liberdade. Porto Alegre: EDIPUCRS, 1997. PINO, A. O Social e o Cultural na Obra de Vigotski. Rev. Educação e Sociedade, ano XXI, $n^{\circ} 71,2000, p p .45-78$.

SHUARE, M. La Psicología Soviética tal Cómo Yo la Veo. Moscou: Editorial Progresso, 1990.

VIGOTSKI, L.S. The Collected Works of L. S. Vygotsky (volume 6). Nova lorque: Kluver Academic/ Plenum Publishers, 1999a.

. A Construção do Pensamento e da Linguagem. São Paulo: Martins Fontes, 2001.
O Desenvolvimento Psicológico na Infância. São Paulo: Martins Fontes, 1999b.

Referências Fontes, 1994

. A Formação Social da Mente. São Paulo: Martins

História do Desenvolvimento das Funções Psíquicas Superiores. In Obras Escogidas III. Madrid: Visor Distribuiciones, 1995.

Hispanica, 1987.

La Imaginación y el Arte en la Infancia. México-DF:

. Psicologia Concreta do Homem. Rev. Educação e Sociedade, ano XXI, $n^{\circ} 71,2000$, pp.23-44.

Fontes, 1996

Teoria e Método em Psicologia. São Paulo: Martins 